\title{
COVID-19: Expanding the Culture of Teaching Mathematics
}

\author{
Zachary Denton* \\ North Carolina Agricultural and Technical State University, Greensboro, NC, United States
}

Keywords: COVID-19, culture, education, online learning, learning technology, mathematics education

\section{INTRODUCTION}

The culture of teaching mathematics has remained inert for many years. Mathematics instructors have generally been reluctant to embrace distance learning, begrudgingly offering online sections for lower-level courses while strongly opposing such delivery for higher-level courses (Allen and Seaman, 2012; Yang, 2017). The argument for opposition is that these courses require a culture of in-person lecturing and one-on-one mentoring to adequately demonstrate the material. While there may be merit to this rationale in heavily theoretical courses, courses that have substantial visual components can greatly benefit from breaking with oratory traditions and embracing online delivery methods.

The onset of COVID-19 forcing classes online provides an opportunity for mathematics instructors to experience the benefits of virtual learning first-hand. Prior to the COVID-19 outbreak, I had delivered online sections for Calculus 1 and 2, but through the transition I was able to develop an online section of Calculus 3. In doing so, I found that the lectures made for online

OPEN ACCESS

Edited by:

Davide Girardelli,

University of Gothenburg, Sweden

Reviewed by:

Niki Murray

Massey University Business School,

New Zealand

*Correspondence:

Zachary Denton

zdenton@ncat.edu

Specialty section:

This article was submitted to

Culture and Communication,

a section of the journal

Frontiers in Communication

Received: 10 December 2020

Accepted: 09 April 2021

Published: 17 May 2021

Citation:

Denton Z (2021) COVID-19:

Expanding the Culture of Teaching

Mathematics.

Front. Commun. 6:640181.

doi: $10.3389 / f c o m m .2021 .640181$ delivery for this class were superior to those I presented in face-to-face sections, due in part to the heavier weighted visual component in Calculus 3 compared to its earlier counterparts. Therefore, I posit that mathematics courses with substantial visual elements can benefit considerably from expanding the culture of teaching mathematics to include distance learning.

\section{BACKGROUND ON CALCULUS 3}

Calculus 3 is a class where comprehending visuals is a primary focus. The mathematics in the course is theoretically similar to Calculus 1 and 2, but Calculus 3 takes these previously learned calculus methods and applies them to multiple dimensional problems (c.f., Stewart et al., 2020). Specifically, the limitations of possible applications from Calculus 1 and 2 are expanded to allow the application of calculus theory to $3 \mathrm{D}$ space along with a time variable. Applications in Calculus 3 are thus far more realistic; however, with this advancement comes the complication of visualizing the frameworks. To wit, a major focus of the course is developing techniques to visualize three-dimensional objects using two-dimensional media (e.g., paper, white boards, and computer screens). This is the first-time students are expected to formally tackle 3D visualizations in Calculus and as such it presents an unprecedented challenge for many of them (Weber and Thompson, 2014; Martinez-Planell et al., 2015).

Prior to COVID-19, I can find no record of Calculus 3 or any higher-level math course being offered online at my institution. However, the transition to online learning in the Spring 2020 semester forced instructors to adapt all math courses to an online environment extemporaneously. Further, it meant that math courses would be offered fully online for the foreseeable future beginning Summer 2020. Leaning on the social presence literature for guidance, my experience teaching Calculus 3 fully online helped me understand the potential for creating a strong and effective online learning experiences in advanced mathematics courses. 


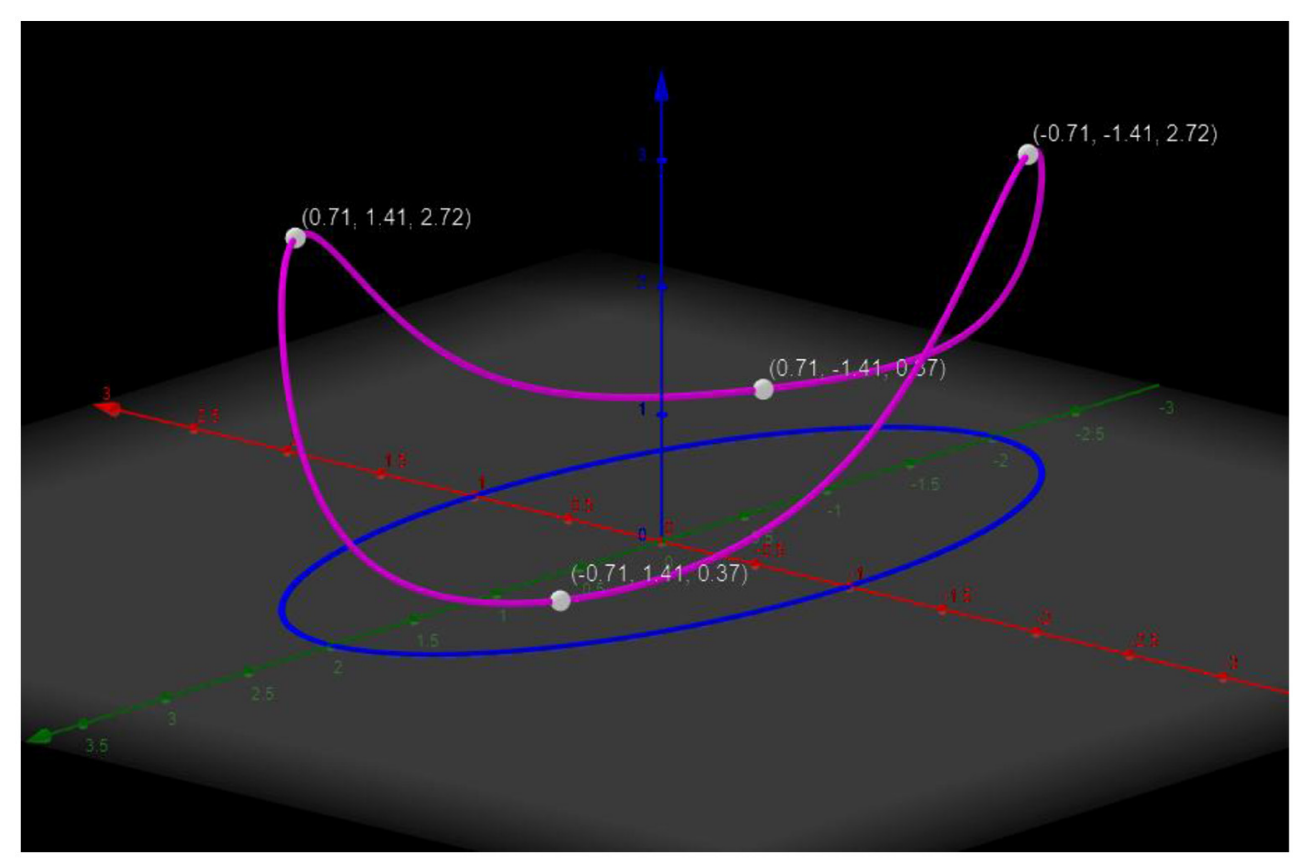

FIGURE 1 | Example constructed using GeoGebra.

\section{BUILDING CALCULUS 3 FOR ONLINE DELIVERY}

Social presence is the degree to which a mediated communication experience feels like a face-to-face experience (Bracken and Lombard, 2004). That means for an online student, the more social presence developed in a classroom, the more the online learning experience feels like a face-to-face learning experience (Kelly and Westerman, 2016). The Community of Inquiry Model of social presence dictates that to develop social presence in the online classroom, instructors should engage in communication practices that are:

1. Affective: expressive; sharing emotions, opinions, or ideas

2. Interactive: invites frequent communication

3. Cohesive: uses terms like "we," "our," or "us" (Garrison et al., 2010)

In building online Calculus 3, I searched for ways to diffuse these social presence cues into the classroom. This began with recording lectures before the semester began. I took care with each lecture to describe tasks as what "we're looking at" or "what we need to do next" to infuse cohesive language. It was also my job to make sure that the lessons were not too formal. Unknown to me before studying social presence, my students could benefit from relevant, very brief stories about the content (Kaufmann and Frisby, 2017) that allowed me to use affective communication, but also make myself more of a real person rather than an automated lecture system.

Using screen capturing and editing software, along with digital writing software, and mathematical graphing software, lectures were prepared for housing in the learning management system. Though skeptical at the outset, I quickly found that the lectures crafted using this approach were far more efficacious than any lecture I had previously given in the face-to-face sections of this course. Specifically, with the editing available in the video format, I could mention a three-dimensional object as part of an explanation and then instantly cut to a graph of that object. From there I could freely rotate and zoom in and out to fully explore the object. Further, in the graphing software it is possible to program animations showing how quantities or objects change over time in $3 \mathrm{D}$ space, which is the theoretical bedrock of Calculus 3 (see Figure 1). This allowed me to improve the clarity of my words in a way that was far more efficient than in the face-to-face environment.

To be clear, using these supportive graphs or animations in Calculus 3 lectures is not unheard of, nor is it novel since I have developed comparable visual representations in my previous sections of the course. However, presenting these visuals in the middle of an in-person lecture is often time consuming, with the class often waiting for an ornery computer to work or timing out for handouts to be distributed to each student. With the adeptness granted by video editing, the presentation of the most appropriate visualizations was prompt, and thus each virtual lecture could include more such visualizations than possible in a comparable face-to-face lecture.

It can be argued that such efficiency may make these lectures too dense to be effective. However, this offers another advantage of the medium, specifically that videos can be paused, rewound, and watched multiple times, an advantage that is not possible with face-to-face lectures. Following the Community of Inquiry 
Model, it became clear that part of my job once the semester started was to emphasize this very benefit with my students. Specifically, it was my job to encourage them to pause, rewind, or rewatch these videos, taking advantage of their ability repeat the communication or take the lessons at their own pace. Second, it was also my job to remind students regularly that they were welcome to email or meet with me through Zoom to ask questions. Both of these jobs captured the interactivity component of social presence.

Notably, I also had to encourage students to ask questions because a substantive disadvantage to this method is that students cannot ask questions and get immediate answers during the lectures like they can during in-person lectures. This meant that being available to my students when they needed me made teaching online far more time consuming than face-to-face. Students in asynchronous courses access lectures at all times of the day, and as they are learning math, they cannot progress in their understanding until their questions were answered. This means that committing to interactive communication is a time-consuming endeavor, but one critically impactful on their learning experience.

\section{DISCUSSION}

The instructional concepts described here are not new to the world of communication research. Communication scholars have long known that online instruction can be just as effective as face-to-face instruction, if not more effective, provided the course is delivered in accordance with the needs of online course learners (c.f., Kelly and Westerman, 2016). This means that online delivery of any course can theoretically be more effective than face-to-face learning if the instructor uses the technology optimally and communicates effectively (Kelly and Westerman, 2016). However, these studies appear to allude most mathematics instructors, and most STEM faculty at large, yet have the potential to bolster the teaching culture across fields.

In my own class, I perceived improved student motivation and engagement. Overall students were more focused on critical thinking and conceptual understanding over rote memorization of procedural methods. In fact, I observed less reliance on publisher provided learning aids such as the Help Me Solve

\section{REFERENCES}

Allen, I. E., and Seaman, J. (2012). Conflicted: Faculty and Online Education, 2012. Babson Park, MA: Babson Survey Research Group.

Amresh, A., Carberry, A. R., and Femiani, J. (2013). "Evaluating the effectiveness of flipped classrooms for teaching CS1," in Proceedings from 2013 IEEE Frontiers in Education Conference (Oklahoma City, OK).

Bracken, C. C., and Lombard, M. (2004). Social presence and children: praise, intrinsic motivation, and learning with computers. J. Commun. 54, 22-37. doi: 10.1111/j.1460-2466.2004.tb0 2611.x

Garrison, D. R., Anderson, T., and Archer, W. (2010). The first decade of the community of inquiry framework: a retrospective. Internet High. Educ. 13, 5-9. doi: 10.1016/j.iheduc.2009.10.003 feature of Pearson's online course delivery tools, a crutch many students are over reliant on. Instead, more students engaged with me directly and exhibited a curiosity of the material beyond the algorithmic steps.

With the sudden shift to online instruction due to COVID19, along with the increasing demand for online programs, mathematics instructors will need to be open to the culture of online learning in order to better serve their students now and in the future. Additionally, the utilization of edited lecture videos is not only applicable to online courses. In fact, such lectures could be implemented in face-to-face courses by delivering a flipped class. In such a class, the lectures would be viewed outside of class, and class time would be devoted to active learning assignments moderated by the instructor. This method would integrate the advantages from the culture of the online class along with the advantages of in-person mentoring and grouped active learning. Flipped classes have been found to increase student motivation and performance in STEM courses and students often have improved performance in flipped classrooms compared to traditional classrooms (Amresh et al., 2013; Herreid and Schiller, 2013). Further, with active learning at the core of flipped classrooms, it has also been shown that active learning improves student performance, motivation, and retention in STEM classrooms (Prince, 2004; Michael, 2006).

Whether incorporated in online classes as the featured delivery of content, or as supplemental resources in a face-toface class, the development of mindfully edited lecture videos that follow social presence guidelines can improve the culture of teaching mathematics classroom as seen in communication literature and through my anecdotal experience during the transition to online instruction due to COVID-19. My aspiration is that my peers can use my example and experience in order to implement recorded lectures within their visually intensive mathematics courses, and in so change the culture of teaching mathematics so that we meet the students where they need us, not only where we the faculty are comfortable.

\section{AUTHOR CONTRIBUTIONS}

The author confirms being the sole contributor of this work and has approved it for publication. 
Prince, M. (2004). Does active learning work? A review of the research. J. Eng. Educ. 93, 223-231. doi: 10.1002/j.2168-9830.2004.tb00809.x

Stewart, J., Clegg, D. K., and Watson, S. (2020). Calculus: Early Transcendentals, 8th Edn. Boston, MA: Cengage Learning.

Weber, E., and Thompson, P. W. (2014). Students' images of twovariable functions and their graphs. Educ. Stud. Math. 87, 67-85. doi: 10.1007/s10649-014-9548-0

Yang, D. (2017). Instructional strategies and course design for teaching statistics online: perspectives from online students. Int. J. STEM Educ. 4:34. doi: 10.1186/s40594-017-0096-x
Conflict of Interest: The author declares that the research was conducted in the absence of any commercial or financial relationships that could be construed as a potential conflict of interest.

Copyright $($ C) 2021 Denton. This is an open-access article distributed under the terms of the Creative Commons Attribution License (CC BY). The use, distribution or reproduction in other forums is permitted, provided the original author(s) and the copyright owner(s) are credited and that the original publication in this journal is cited, in accordance with accepted academic practice. No use, distribution or reproduction is permitted which does not comply with these terms. 